\title{
Reabilitação oral por meio de intervenções múltiplas: relato de caso clínico
}

No Brasil há uma grande demanda por atendimento odontológico devido a uma série de comprometimentos orais, que acabam prejudicando o bem-estar físico e emocional do paciente, influenciando diretamente sua qualidade de vida. O principal comprometimento é o estético, dado pelo edentulismo que pode ser causada por vários fatores, sendo a cárie a principal, caracterizada pela destruição dos tecidos dentários saudáveis pela combinação da tríade: microrganismo, susceptibilidade e tempo. Outro grande fator é a doença periodontal, que consiste na inflamação e destruição dos tecidos de suporte dos dentes acometidos por microrganismos presentes na área, evoluindo para uma mobilidade dental, causando em última instância a perdas dentárias. Tais condições necessitam de uma intervenção múltipla, pelo processo restaurador, associado a raspagens e por fim a reabilitação com uso de próteses dentárias. O objetivo desse trabalho é relatar o caso de um paciente com comprometimento oral estético e funcional em decorrência de periodontite crônica, lesões de cárie e prótese parcial mal adaptada, o mesmo recebeu intervenções multidisciplinares para sua reabilitação oral. Como conclusão, verificou-se importância de uma avaliação minuciosa para desenvolve o plano de tratamento adequado, podendo ser necessário um tratamento múltiplo em diferentes áreas da odontologia, sempre levando em consideração individualidades, como a expectativas do paciente e as questões biológicas, considerando o impacto na qualidade de vida e na sua autoestima como um fator subjetivo e de fundamental importância para se atingir o sucesso do tratamento.

Palavras-chave: Reabilitação Oral; Periodontia; Prótese.

\section{Oral rehabilitation through multiple interventions: case report}

Brazil's have a great demand for dental care due to a series of oral compromises, which end up harming the patient's physical and emotional well-being, directly influencing their quality of life. The main compromise is esthetic, given by edentulism that can be caused by several factors, being the main caries, characterized by the destruction of healthy dental tissues by the combination of the triad: microorganism, susceptibility and time. Another major factor is periodontal disease, which consists of inflammation and destruction of the supporting tissues of teeth affected by microorganisms present in the area, evolving into dental mobility, ultimately causing tooth loss. Such conditions require multiple intervention, through the restorative process, associated with scraping and finally rehabilitation with the use of dental prostheses. The objective of this study is to report the case of a patient with aesthetic and functional oral impairment due to chronic periodontitis, caries lesions and poorly adapted partial prosthesis. He received multidisciplinary interventions for his oral rehabilitation. In conclusion, the importance of a thorough evaluation to develop the appropriate treatment plan was verified, and multiple treatment may be necessary in different areas of dentistry, always taking into consideration individualities, such as patient expectations and biological issues, considering the impact on quality of life and selfesteem as a subjective and fundamentally important factor to achieve treatment success.

Keywords: Oral Rehabilitation; Periodontics; Prosthesis.

Topic: Notas Científicas

Reviewed anonymously in the process of blind peer.
Received: 24/06/2019

Approved: 12/09/2019
Larissa Lima Teixeira (iD)

Instituto Macapaense de Ensino Superior, Brasil

http://lattes.cnpq.br/1063120454966625

http://orcid.org/0000-0003-0428-5720

larissaapteixeira@gmail.com

Brenda Matsunaga Laurindo (iD

Instituto Macapaense de Ensino Superior, Brasil

http://lattes.cnpq.br/6687511503501079

http://orcid.org/0000-0002-3431-8493

brenda.matsunaga@hotmail.com

\section{Referencing this:}

TEIXEIRA, L. L.; LAURINDO, B. M.. Reabilitação oral por meio de intervenções múltiplas: relato de caso clínico. Scire Salutis, v.9, n.3, p.33-38, 2019. DOI: http://doi.org/10.6008/CBPC22369600.2019.003.0005 


\section{INTRODUÇÃO}

No Brasil há uma procura muito grande da população a atendimento odontológico devido a algum tipo de comprometimento oral, que muitas vezes acaba prejudicando o bem-estar físico e emocional do paciente, influenciando na qualidade de vida (BARRETO et al., 2019). O principal comprometimento é o estético, dado pela perda dentária que pode ser causada por vários fatores, como, a cárie dental, as doenças periodontais e até a falta de conscientização da população sobre os cuidados com a higiene oral, o que leva ao grande número de tratamentos reabilitadores com uso de próteses dentárias (SOARES et al., 2012).

A cárie dental é considerada o principal fator que leva a perda dentária, sendo caracterizada pela destruição dos tecidos saudáveis do dente. Outro grande fator é a doença periodontal, que é identificada pela inflamação e destruição dos tecidos de suporte dos dentes acometidos por microrganismos presentes na área levando a essa condição, evoluindo para uma mobilidade dental, causando possíveis perdas dentárias (MARQUES et al., 2014). O edentulismo é resultado de doenças e condições que afetam o complexo bucal. 0 principal objetivo da prótese dentária é reestabelecer saúde bucal através da reabilitação mastigatória, fonética e estética (CAMBIAGHI et al., 2014).

Tanto a dentística como a periodontia, que participam de processos interdisciplinares, estão presentes no preparo pré-protético, que pode ser definido como um conjunto de procedimentos que visam o preparo do meio bucal para receber a prótese dentária. A exodontia é um tipo de intervenção cirúrgica muitas vezes necessária durante o preparo pré-protético (TOLENTINO et al., 2018). Dentre os tratamentos de reabilitação oral, a prótese dentária encontra-se entre as opções de tratamento, mostrando altas taxas de sucesso, exercendo um papel fundamental para a melhoria da saúde bucal por devolver a função de mastigação, fonação e estética (CORRÊA et al., 2016).

Em se tratando de pacientes edêntulos, a restauração estética também tem um importante efeito psicológico, melhorando a sua autoestima e autoconfiança, sendo, portanto, parte fundamental do tratamento reabilitador oral (BARBOSA et al., 2006). Sendo o conceito do belo de caráter pessoal e subjetivo, sofrendo influências culturais e sociais, a individualidade do paciente deve ser levada em consideração e sempre respeitada pelo profissional, permitindo um tratamento funcional com característica individual, que pode ser buscada por meio da utilização de diferentes arranjos dentários de acordo com o gosto pessoal do paciente (MARQUES et al., 2014).

Logo, é de grande importância ter o conhecimento sobre as percepções e expectativas de cada paciente para conseguir o sucesso após a conclusão do tratamento, bem como investigar sua satisfação com os resultados conquistados, levando os profissionais de saúde a se preocuparem não só com a integridade física, mas também com a mental e a qualidade de vida de quem procura os seus serviços, permitindo um trabalho de excelência por meio de um tratamento multiprofissional. Sendo assim, o objetivo desse trabalho é relatar o caso de um paciente com comprometimento oral estético e funcional em decorrência de periodontite crônica, lesões de cárie e prótese parcial mal adaptada, o mesmo recebeu intervenções multidisciplinares para sua reabilitação oral. 


\section{RELATO}

Paciente do sexo masculino, 63 anos, compareceu a clínica odontológica da Universidade Estadual do Oeste do Paraná, tendo como queixa principal a insatisfação com a estética do sorriso e falta de adaptação da prótese superior. Durante exame clínico, constatou-se o seguinte quadro clínico: ausência dos elementos superiores: $18,17,15,22,26,27$ e 28 . Na arcada inferior o mesmo só possuía a dentição de canino a canino. Os Elementos 15 e 45 apresentaram lesão de furca, com mobilidade grau III e o elemento 21 com coroa encurtada associada a extensa perda coronária. Paciente com quadro de periodontite crônica generalizada, com uso de prótese parcial superior mal adaptada e ausência de prótese inferior. Durante anamnese, ausência de comprometimentos sistêmicos.

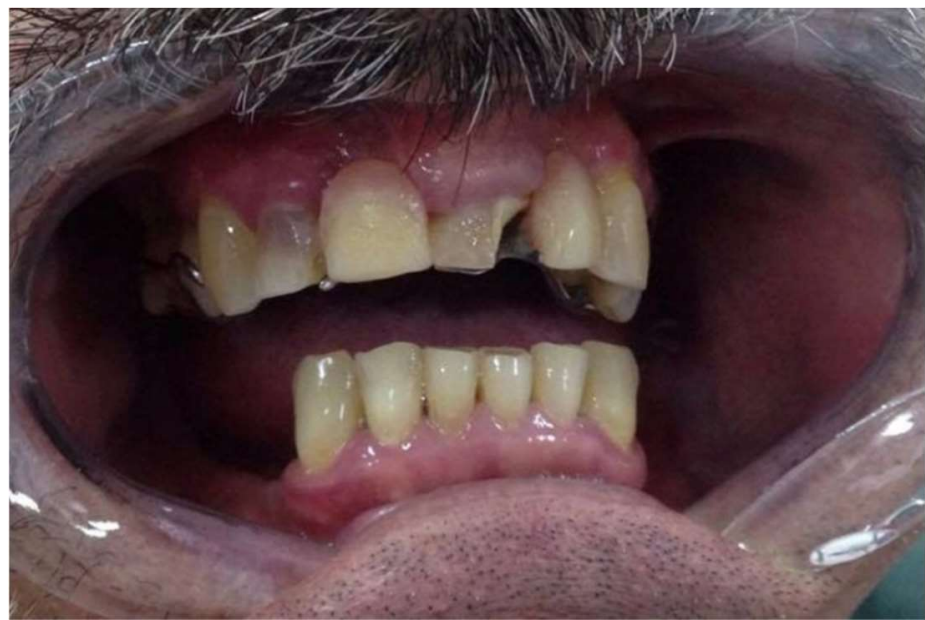

Figura1: Vista frontal do aspecto inicial do paciente com uso da prótese parcial removível superior.
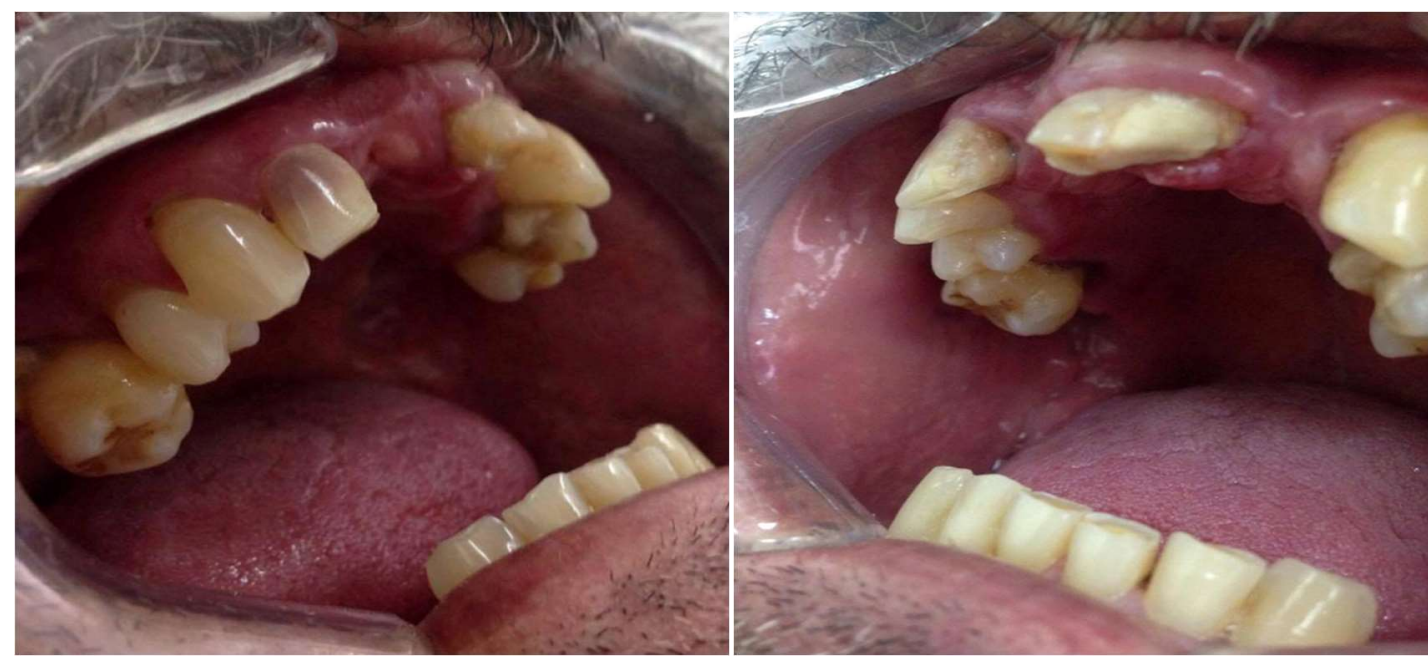

Figura 2: Vistas laterais do aspecto inicial do paciente sem o uso da prótese parcial removível superior. 


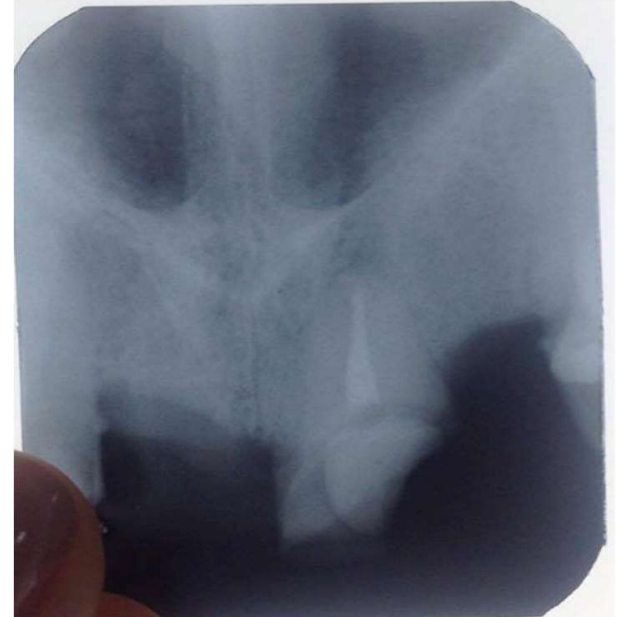

Figura 3: Apecto radiográficoinicial do elemento 21, onde é possível verificar a coroa encurtada associada a grande perda de estrutura coronária.

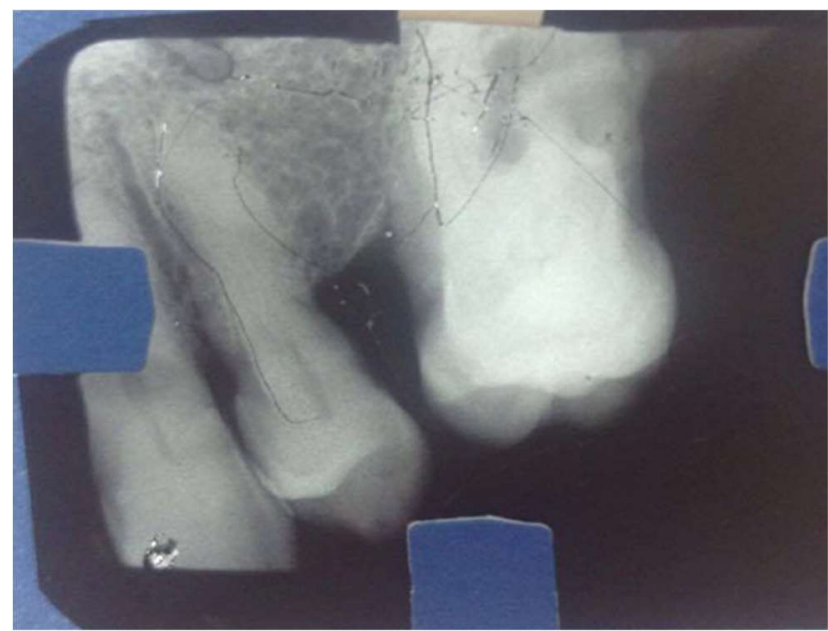

Figura 4: Aspecto radiográfico do elemento 16, onde é possível verificar perda de inserção horizontal de $1 / 3$ na mesial e 2/3 na distal. Clinicamente, dente com elevada mobilidade.

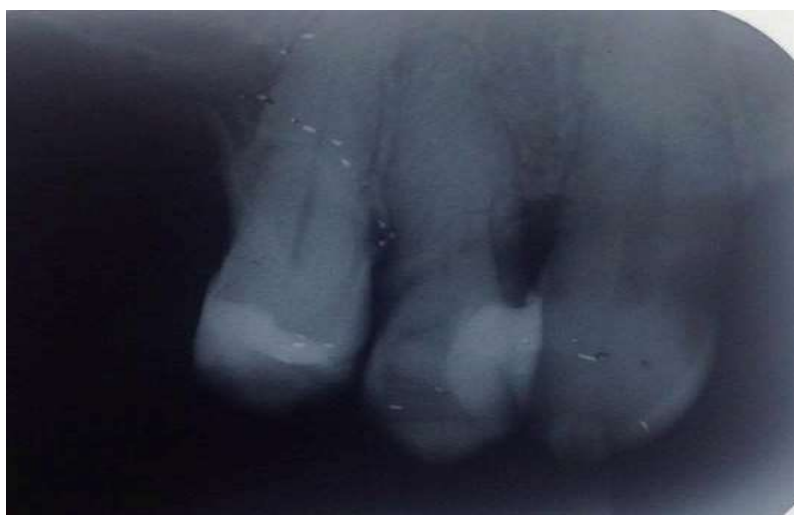

Figura 5: Aspecto radiográfico do elemento 25, onde é possível verificar perda de inserção horizontal de $1 / 3$ na mesial e $2 / 3$ na distal. Clinicamente, dente com elevada mobilidade.

\section{Tratamento}

Foi realizada a reabilitação oral por meio de intervenções múltiplas. Inicialmente, realizou-se uma adequação do meio por via das exodontias dos elementos 16 e 25 e do 21 (devido a impossibilidade reabilitadora por meio de uma coroa associada a pino, justificada pelo encurtamento radicular). Realizou-se também o tratamento periodontal de todos os elementos por meio de raspagens supragengivais e subgengivais, por fim, realizou-se a confecção de uma nova prótese parcial removível superior, agora, aliada a uma prótese inferior. Aspecto final do paciente é mostrado na figura 6.

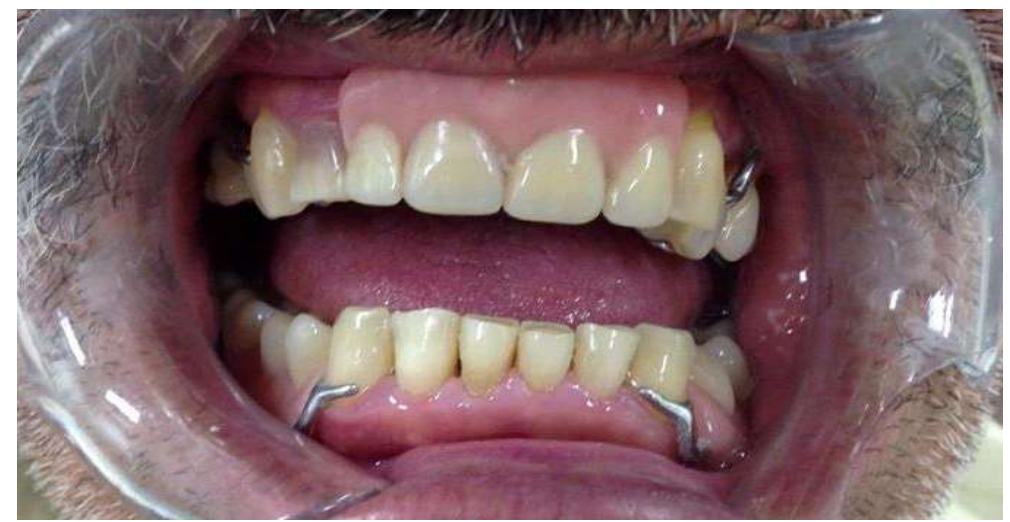

Figura 6: Aspecto final do paciente, com as próteses parciais removíveis já instaladas. 


\section{DISCUSSÃO}

Profissionais na odontologia reabilitadora encontram situações clínicas onde nem sempre o sucesso é alcançado somente com a devolução da função mastigatória por meio de uma prótese convencional. A busca pelo sucesso muitas vezes requer a associação ademais áreas da odontologia para formar um tratamento integrado (SOARES et al., 2012). Muitas vezes é preciso analisar o caso e ver os critérios clínicos e sociais para a indicação de exodontias, além da avaliação de reabilitação em pacientes edêntulos parciais, entendendo que fatores influenciam na situação (TOLENTINO et al., 2018). O sucesso do tratamento abordado, é resultante de uma intervenção em múltiplas áreas da odontologia.

Um bom planejamento odontológico requer a integração interdisciplinar, visando modernizar a odontologia e melhorar a qualificação do profissional, enquadrando outras ideias a serem realizadas, conseguindo assim, um resultado esperado (SOARES et al., 2012). A prótese parcial removível como tratamento reabilitador pode melhorar a qualidade de vida e autoestima do paciente, essa modalidade, comparado a tratamentos individuais, pode ser vantajosa para o paciente por ser viável e de baixo custo, suprindo a falta de estética e falhas funcionais causadas pelo edentulismo (GOIATO et al., 2013)

No que diz respeito à expectativa dos pacientes em face à reposição protética dos dentes, as preocupações mais frequentes envolvem a qualidade da prótese, especialmente quanto à estabilidade, adaptação e ter sua identidade anterior adquirida novamente. Os pacientes frequentemente relatam dificuldade inicial em se acostumar com o aparelho protético. Palavras como 'dor', 'incômodo', 'sensação de estar machucando' são comumente pontuadas (SILVA et al., 2016). No caso clínico em questão, o paciente já possuía experiência com prótese parcial removível superior, relatando haver grande melhora no aspecto mastigação e estética quando associada a uma prótese inferior. O mesmo não relatou incomodo em nenhuma das etapas de adaptação.

Ainda sobre aspectos clínicos, a reabilitação protética também parece guardar relação com a autopercepção bucal. Assim, o uso de próteses removíveis pode reduzir a percepção ruim dos impactos gerados pelo edentulismo na saúde bucal (SOUZA et al., 2016). A expectativa do paciente frente a qualquer tipo de tratamento, principalmente estético, deve ser considerada como um fator importante para o resultado final, o que pode levá-lo a construir expectativas, que quando não alcançadas, causam insatisfação em relação ao tratamento (CARVALHO et al., 2019).

Vale ressaltar, o destaque ao aspecto da humanização, estreitando laços entre profissional e paciente, ressaltando a relevância da ausculta do profissional no sentido de transcender a técnica de confecção de próteses para um processo de reabilitação integral do indivíduo, alcançando assim o tão esperado sucesso reabilitador (SILVA et al., 2016).

\section{CONCLUSÕES}

A associação das áreas da odontologia no tratamento interdisciplinar é ideal para reparar a saúde e bem-estar do paciente, porque além da função mastigatória, a estrutura dos dentes adjacentes e dos tecidos 
de suporte são importantes para alcançar a reintegração e satisfação do paciente. $O$ dentista deve avaliar qual será o melhor tratamento para cada paciente podendo ser necessário um tratamento multidisciplinar, sempre levando em consideração individualidades, como a expectativas do paciente e as questões biológicas, não deixando de considerar o impacto na qualidade de vida do paciente e na sua autoestima como um fator subjetivo e de fundamental importância para se atingir o sucesso do tratamento.

\section{REFERÊNCIAS}

BARBOSA, D. B.; BARÃO, V. A. R.; ASSUNÇÃO, W. G.; GENNARI FILHO, H.; GOIATO, M. C.. Complete denture insertion: A review. Rev. Odontol Unesp, v.35, n.1, p.53-60, 2006.

BARRETO, J. O.; SOUSA, M. L. A.; SILVA JÚNIOR, S. E.; FREIRE, J. C. P.; ARAÚJO, T. N.; FREITAS, G. B.; RIBEIRO, E. D.. Impactos psicossociais da estética dentária na qualidade de vida de pacientes submetidos a próteses: revisão de literatura. 8 ed. Archhealthinvest, 2019.

CAMBIAGHI, L.; ZANGRANDO, M. S. R.; REZENDE, M. L. R.. Periodontia na priorização estético-funcional de próteses implanto suportadas. Bauru: USP, 2014.

CARVALHO, L. F.. O impacto do Edentulismo na qualidade de vida de pacientes edêntulos. R. ACBO, v.8, p.40-48, 2019.

CORRÊA, H. W.; BITENCOURT, F. V.; NOGUEIRA, A. V.; TOASSI, R. F. C.. Saúde bucal em usuários da atenção primária: análise qualitativa da autopercepção relacionada ao uso e necessidade de prótese dentária. Physis: Revista de Saúde Coletiva, v.26, n.2, p.503-524, 2016.

GOIATO, M. C.; SANTOS, D. M.; MEDEIROS, R. A.; LAURINDO JUNIOR, M. C. B.; WATANABE, D.. Reabilitação protética com associação entre prótese parcial removível e implante dentário: relato de caso. Revista odontológica de Araçuba, v.34, n.2, p.67-69, 2013.

MARQUES, L. A. R. V.; LEITÃO, L. M. A.; GOMES, J. B.; LOPES, R. H. M. G.; SILVA, M. K. O.; ROCHA, J. E. T.. The esthetic influence of the dental arrangements in complete denture. Literature Review v.24, n.1, p.26-32, 2014.

SILVA, E. A.; BATISTA, M. J.; SOUSA, M. L. R.. Impacto da saúde bucal na qualidade de vida de adultos de diferentes níveis socioeconômicos. Revista Ciências Médicas, v.1, n.25, p.11-21, 2016

SOARES, M. S.; ROMANO, M. M.; ADDE, C. A.; DOMINGUEZ, G. C.; MOREA, C.. Abordagem interdisciplinar em reabilitação bucal. Revista de Associação Paulista de Cirurgiões Dentistas, São Paulo, v.66, n.4, p.260-267, 2012.

SOUZA, J. G. S.. Auto percepção da necessidade de prótese dentária total entre idosos brasileiros desdentados. Ciência \& Saúde Coletiva, v.21, n.11, p.3407-3415, 2016.

TOLENTINO, P. H. M. P.. Fatores que influenciam na tomada de decisão para a indicação de exodontias e do tipo de tratamento reabilitador em casos de edentulismo parcial com dentes periodontalmente afetados. Dissertação (Mestrado em odontologia, área de concentração clínica odontológica) - Universidade federal de goiás, Goiânia, 2018.

A CBPC - Companhia Brasileira de Produção Científica (CNPJ: 11.221.422/0001-03) detém os direitos materiais desta publicação. Os direitos referem-se à publicação do trabalho em qualquer parte do mundo, incluindo os direitos às renovações, expansões e disseminações da contribuição, bem como outros direitos subsidiários. Todos os trabalhos publicados eletronicamente poderão posteriormente ser publicados em coletâneas impressas sob coordenação da Sustenere Publishing, da Companhia Brasileira de Produção Científica e seus parceiros autorizados. Os (as) autores (as) preservam os direitos autorais, mas não têm permissão para a publicação da contribuição em outro meio, impresso ou digital, em português ou em tradução. 